\title{
QUÍMICA MEDICINAL MODERNA: DESAFIOS E CONTRIBUIÇÃO BRASILEIRA
}

\author{
Lídia M. Lima"
}

Faculdade de Farmácia, Universidade Federal do Rio de Janeiro, CP 68006, 21944-910 Rio de Janeiro - RJ, Brasil

\begin{abstract}
MODERN MEDICINAL CHEMISTRY: CHALLENGES AND BRAZILIAN CONTRIBUTION. The main aspects of the modern Medicinal Chemistry, among the classic and industrial paradigms, used in the drug discovery process will be treated. The contribution of the Brazilian science in the knowledge generation in Medicinal Chemistry will be demonstrated, with base in searches accomplished in the portal Web of Science ${ }^{\circledast} 7.10$ and in the directory of groups of research of CNPq.
\end{abstract}

Keywords: medicinal chemistry; prototype; pharmaceutical industry.

\section{PREÂMBULO}

Neste artigo serão tratados, de forma não exaustiva, os aspectos principais da Química Medicinal moderna, definindo as diferenças e áreas de sobreposição entre os paradigmas clássico e industrial aplicados ao processo da descoberta de fármacos. A inovação e a crise de produtividade nas indústrias farmacêuticas, associada à característica específica do paradigma industrial, serão discutidas. Estratégias modernas para a identificação do compostoprotótipo, etapa-chave do processo da descoberta de fármacos e objetivo primário da Química Medicinal serão comentadas. A contribuição da ciência brasileira na geração de conhecimento em Química Medicinal será demonstrada, com base em buscas realizadas no portal Web of Science ${ }^{\circledR} 7.10$ e no diretório de grupos de pesquisa do CNPq, permitindo o mapeamento das instituições de ensino superior e instituições de pesquisa nacionais produtoras de conhecimento na área.

\section{INTRODUÇÃO}

A Química Medicinal, segundo definição da IUPAC, é uma disciplina baseada na química, envolvendo aspectos das ciências biológica, médica e farmacêutica, cuja missão é o planejamento, descoberta, invenção, identificação e preparação de compostos biologicamente ativos (protótipos), o estudo do metabolismo, interpretação do mecanismo de ação a nível molecular e a construção das relações entre a estrutura química e a atividade farmacológica (SAR) [http://www.chem.qmul.ac.uk/iupac/medchem/].

Um projeto de Química Medicinal compreende as etapas de descoberta, otimização e desenvolvimento do protótipo ${ }^{1}$.

Entende-se por descoberta a etapa destinada à eleição do alvo terapêutico, útil para o tratamento de uma determinada fisiopatologia, a aplicação de estratégias de planejamento molecular para desenho de ligantes do alvo selecionado - utilizando as estratégias de modificação molecular clássicas da Química Medicinal, tais como bioisosterismo, homologação, simplificação e hibridação molecular ${ }^{2-4}$, ou pelo emprego de técnicas computacionais como a modelagem molecular e o QSAR. Compreende, ainda, realizar a determinação das atividades farmacológicas do ligante, que uma vez ativo in vivo, preferencialmente por via oral, passa a ser denominado protótipo.

*e-mail: lidia@pharma.ufrj.br

\#LASSBio - Laboratório de Avaliação e Síntese de Substâncias Bioativas
A etapa de otimização compreende o melhoramento da estrutura do protótipo, através de modificações planejadas com auxílio de técnicas definidas - que podem identificar os diferentes níveis de contribuição farmacofórica, fornecer informações sobre a conformação bioativa e antecipar o índice de reconhecimento molecular pelo alvo selecionado - visando o aumento da potência, seletividade, diminuição da toxicidade, adequação do perfil farmacocinético (absorção, distribuição, metabolismo, excreção e toxicidade, ADMET) e estabelecimento da SAR, a partir da síntese e avaliação farmacológica, in vitro e in vivo, de séries congêneres ao protótipo identificado originalmente $e^{1,2}$.

A etapa de desenvolvimento do protótipo objetiva a otimização de suas propriedades ADMET e farmacêuticas (solubilidade, odor, sabor), de modo a viabilizar seu uso clínico, através da preparação eventual de pró-fármacos, complexos de inclusão, microemulsões, formulações de liberação lenta, entérica etc. ${ }^{1}$.

\section{O papel do paradigma clássico versus paradigma industrial no processo da descoberta de fármacos}

O processo da descoberta de fármacos, nas indústrias farmacêuticas, sofreu profunda reestruturação e mudança de paradigmas, quando comparamos o modelo empregado na década de 50 até o final da década de 80 em relação ao modelo vigente.

No período de 1950-1980 o Químico Medicinal com apoio do colaborador Farmacologista eram os pilares dos programas de pesquisa em Fármacos. As estratégias de modificação molecular - típicas da Química Medicinal - foram implementadas e os princípios racionais do processo de otimização do composto-protótipo estabelecidos e empregados, pela primeira vez, a partir da aplicação da estratégia de bioisosterismo 4 .

Nas décadas de 60 e 70, a determinação de estruturas protéicas por difração de raios-X (e.g. mioglobina e hemoglobina), a produção do primeiro computador de acesso múltiplo - protótipo para o desenvolvimento dos computadores modernos - a criação do "Protein Data Bank (PDB)", o fortalecimento da farmacologia e a aplicação das estratégias de modificação molecular no desenho de novos protótipos criaram o ambiente favorável à descoberta do primeiro fármaco, através da aplicação da estratégia denominada descoberta baseada na estrutura ("structure-base drug discovery") - o captopril $1^{5}$, primeiro fármaco anti-hipertensivo atuando através da inibição da enzima conversora de angiotensina (ECA) (Figura 1). Sua descoberta beneficiou-se dos estudos farmacológicos sobre os efeitos do veneno de serpente brasileira do gênero Bothrops jararaca, realizados pelo grupo de Rocha e Silva e, posteriormente, por Sérgio H. 
Ferreira na Faculdade de Medicina da Universidade de São Paulo, em Ribeirão Preto, demonstrando sua ação vasodilatadora, dependente de sua capacidade em potencializar a atividade da bradicinina ${ }^{6}$. Os princípios ativos, de natureza peptídica, do veneno de Bothrops jararaca foram isolados, sintetizados e testados isoladamente, destacando-se como mais ativo o nonapeptídeo denominado teprotide (SQ-20,881), um inibidor da ECA - enzima responsável pelo metabolismo da bradicinina e pela conversão de angiotensina I em angiotensina $\mathrm{II}^{7}$. Dada a perda de eficácia por administração oral, modificações na estrutura deste protótipo (SQ-20,881) foram realizadas empregando-se estratégias de modificação molecular com base nas informações obtidas a partir do modelo de interação química envolvida no processo de reconhecimento molecular do SB-20,881 pelo sítio ativo da carboxipeptidase-A, metaloenzima - zinco dependente - com elevada similaridade a ECA ${ }^{5}$.

Em 21 de outubro de 2005, a UFRJ homenageou o Prof. Sérgio H. Ferreira, com o título de Honoris Causa, em reconhecimento a sua brilhante contribuição para o avanço da Ciência, incluindo sua colaboração para a descoberta do captopril e da elucidação do mecanismo molecular de ação do ácido acetil salicílico (AAS, Figura 1).
Na década de 80, os avanços da biologia molecular contribuíram para a compreensão dos aspectos bioquímicos associados a várias fisiopatologias, favorecendo o fortalecimento da abordagem de planejamento de fármacos baseado no mecanismo de ação pretendido também conhecida como abordagem fisiológica - consagrada pela descoberta da cimetidina (Figura 1), ainda, na década de $70^{2,8}$. Neste período, observaram-se avanços significativos da espectroscopia de ressonância magnética nuclear $(\mathrm{RMN})^{9}$, embora, a época, poucos alvos terapêuticos fossem acessíveis por esta técnica. Avanços em métodos computacionais para análise do complexo receptor-ligante foram realizados e os conceitos de pontos e grupamentos farmacofóricos foram consolidados. Grupos de planejamento baseado na estrutura ("structure-based design") surgem dentro das indústrias farmacêuticas, agregando-se à equipe de Químicos Medicinais. No final da década, vários destes cientistas, reconhecendo a importância desta estratégia de planejamento molecular de ligantes, criaram novas companhias "start-up", a exemplo da Vertex Pharmaceuticals, Inc. e Agouron Pharmaceuticals, Inc. ${ }^{10}$.

No final dos anos 80 e início da década de 90, o processo da descoberta de fármacos nas indústrias farmacêuticas observou mu-<smiles>CC(CS)C(=O)N1CCCC1C(=O)O</smiles>

captopril<smiles>C=CC1CC2CC1CN2C(O)c1ccnc2ccc(OC)cc12</smiles>
quinina<smiles>CC(=O)Oc1ccccc1C(=O)O</smiles>

AAS<smiles>CNC(=NCl)NCCSCc1nc[nH]c1C</smiles><smiles>CCC1C(=O)OCC1Cc1cncn1C</smiles><smiles>CCCc1nn(C)c2c(=O)[nH]c(-c3cc(S(=O)(=O)N4CCN(C)CC4)ccc3OCC)nc12</smiles><smiles>Cc1ccc(NC(=O)c2ccc(CN3CCN(C)CC3)cc2)cc1Nc1nccc(-c2cccnc2)n1</smiles><smiles>CCOC(=O)N1CCC(=C2c3ccc(Cl)cc3CCc3cccnc32)CC1</smiles><smiles>CC(C)(C)c1ccc(C(O)CCCN2CCC(C(O)(c3ccccc3)c3ccc(Cl)cc3)CC2)cc1</smiles>

terfenadina<smiles>Cc1cc2c(s1)Nc1ccccc1N=C2N1CCN(C)CC1</smiles><smiles>OC(c1cc(C(F)(F)F)nc2c(C(F)(F)F)cccc12)C1CCCCN1</smiles>

mefloquina<smiles>CC(C)(C(=O)O)c1ccc(C(O)CCCN2CCC(C(O)(c3ccccc3)c3ccc(Cl)cc3)CC2)cc1</smiles>

fexofenadina<smiles>Clc1ccc2c(c1)CCc1cccnc1C2=C1CCNCC1</smiles>

Figura 1 
dança significativa em seu modus operandis, estabelecendo-se um novo paradigma - beneficiado pelos avanços em tecnologias analíticas, sintéticas, de caracterização estrutural, da introdução da química combinatorial (QC), do "high-throughput screening (HTS)", biologia molecular, ciências genômicas e ultra-HTS ${ }^{11}$.

Durante o processo da descoberta de fármacos, aplicando-se o paradigma clássico da Química Medicinal, as etapas de eleição da doença, do alvo molecular, síntese, caracterização, purificação, avaliação dos efeitos farmacológicos, toxicológicos, processo de otimização - baseado em estratégias de modificação molecular ou no emprego de ferramentas computacionais - são realizadas in loco. A criatividade e a intuição do Químico Medicinal são essenciais ao sucesso dos programas de descoberta de fármacos ${ }^{10}$.

Várias são as diferenças entre o modus operandis do paradigma clássico, comparado ao paradigma industrial, dito moderno. Três merecem destaque - o processo sintético de obtenção do hit x composto-protótipo, o processo de "screening" farmacológico e a importância dada aos produtos naturais - e serão comentadas a seguir.

Ao longo da década de 80 a limitação da capacidade do Químico Medicinal em preparar e purificar um número cada vez maior de novos compostos, em curto intervalo de tempo, tornou-se evidente. $\mathrm{Na}$ tentativa de maximizar a relação tempo-produção, as indústrias farmacêuticas desenvolveram a estratégia de síntese combinatorial, viabilizando a rápida construção de coleções combinatórias, preparadas por síntese paralela ou na forma de mistura ${ }^{12}$, de centenas ou milhares de compostos/dia. A primeira coleção combinatória ou quimioteca - construída baseada em "scaffold" de fármacos conhecidos - foi introduzida no início da década de $90^{13}$. A partir deste marco, milhares foram preparadas, a maioria por empresas especializadas na geração de quimiotecas combinatórias, a exemplo da Pharmacopeia, Inc. - fundada em Princeton, Nova Jersey. O aumento na velocidade de preparação de novos compostos sintéticos exigiu o desenvolvimento de método de ensaio biológico automatizado, rápido e preciso - o "high throughput screening (HTS)". O uso da química combinatorial (QC) acoplada ao HTS passou a constituir o modelo primário adotado pelas indústrias farmacêuticas para o processo inicial de triagem e identificação de hits (ligantes), ativos in vitro, sobre um alvo molecular definido $a$ priori, muitas vezes sem validação clínica comprovada.

Embora os projetos de descoberta de fármacos - com base nos paradigmas clássico e industrial - estejam fundamentados em um processo inicial de triagem ("screening"), a principal diferença reside na natureza do processo de "screening" empregado. No paradigma industrial a triagem é conduzida em alta velocidade através do emprego do HTS e realizada em modelo in vitro, de ação específica sobre um determinado alvo molecular, viabilizando o teste de amplas quimiotecas combinatórias e resultando na identificação do hit. Na aplicação do paradigma clássico da Química Medicinal o processo de triagem é realizado em modelos funcionais in vivo, denominados modelos de prova de conceito, envolvendo um número significativamente inferior de compostos testados e permitindo a identificação do protótipo - em estágio bem inicial do processo de descoberta de fármacos - com perfil de atividade farmacológica determinada em modelos animais e, freqüentemente, ativo por via oral. Estabelecese, desta feita, o "screening" orientado pelo alvo - empregado pelas indústrias farmacêuticas - versus o "screening" orientado pela doença, característico do paradigma clássico - amplamente utilizado por pesquisadores dos laboratórios das mais prestigiosas instituições de ensino e pesquisa nacionais e internacionais ${ }^{14}$.

Outra diferença significativa no modelo operacional dos paradigmas industrial e clássico refere-se à questão dos produtos naturais, negligenciados no paradigma industrial, e valorizados pelo paradigma clássico, como importante fonte para obtenção e dese- nho de novos fármacos, a exemplo do alcalóide pilocarpina e da mefloquina (Figura 1) - desenhada por aplicação da estratégia de simplificação molecular no protótipo natural quinina ${ }^{2,3}$.

No final dos anos 90, os avanços da biologia molecular, das ciências genômicas e a aplicação da tecnologia do DNA recombinante tiveram papel ímpar no processo de descoberta dos chamados fármacos biotecnológicos ${ }^{15}$. Sucessos como a descoberta da epoetinaalfa $\left(\right.$ Epogen $\left.{ }^{\circledR}\right)$ e da insulina humana recombinante levaram à concepção de que células, quando devidamente manipuladas, são laboratórios vivos para síntese de moléculas bioativas e impulsionaram a criação de importantes empresas de biotecnologia, a exemplo da Genentech, Inc. e Amgen, Inc. - que exploram técnicas de biologia molecular em prol da identificação de novos alvos moleculares e de novos fármacos. O Rituximabe (Rituxan ${ }^{\circledR}$, Genentech), Infliximabe (Remicade ${ }^{\circledR}$, Schering-Plough), Etarnacept (Enbrel ${ }^{\circledR}$, Amgen and Wyeth), omalizumabe (Xolair ${ }^{\circledR}$, Genentech/ Novartis/ Tanox) são exemplos de fármacos biotecnológicos que representam autênticas inovações para o tratamento do câncer, artrite reumatóide e asma.

\section{A inovação e os desafios do processo da descoberta de fármacos, segundo o paradigma industrial}

A descoberta de fármacos, pela indústria farmacêutica, é considerada por especialistas uma atividade complexa, multifatorial, cara, demorada, envolvendo a aplicação de técnicas e metodologias modernas, e cuja produtividade é questionada com base em dados que demonstram a relação inversamente proporcional entre os investimentos em Pesquisa e Desenvolvimento (P\&D) e a descoberta de NCEs ("New Chemical Entities") ${ }^{16}$.

Ao longo das últimas décadas, o processo da descoberta de fármacos, segundo o paradigma industrial, presenciou e beneficiou-se do advento de várias novas tecnologias, acompanhadas da premissa de que sua introdução levaria à obtenção de um número maior de fármacos, com redução de custos. Entretanto, a despeito do significativo aumento dos investimentos em $\mathrm{P} \& \mathrm{D}$, do impacto do projeto Genona Humano e do inquestionável avanço das tecnologias empregadas no processo da descoberta de fármacos, a produtividade da Indústria Farmacêutica, mensurada por sua capacidade em introduzir no mercado novos fármacos, vem observando significativo declínio na última década ${ }^{16}$.

Análise da produtividade das multinacionais farmacêuticas, aferida por sua capacidade inovadora, revela uma tendência ao maior número de inovações incrementais em relação às inovações radicais. Entretanto, a descoberta de uma inovação radical aumenta os lucros e serve de modelo para a criação, posterior, de uma ou mais inovações incrementais. Esta nova realidade resulta do reconhecimento dos desafios, riscos e maior incidência de insucessos para a introdução no mercado de fármacos inovadores, utilizando o paradigma industrial de descoberta de fármacos. Por estas razões, as grandes multinacionais farmacêuticas confiam nas inovações incrementais, os chamados fármacos "me-too" ou cópias terapêuticas, como forma de assegurar lucros e competitividade industrial ${ }^{17}$.

Entre os anos de 1990 a 2003, o Centro para Avaliação e Pesquisa de Fármacos ("Drug Evaluation and Research, CDER") da agência norte americana "Food and Drug Administration (FDA)" aprovou 1.171 novas aplicações de fármacos ("New Drug Applications, NDAs"), deste total apenas 34\% correspondiam a novas entidades moleculares ("New Molecular Entities, NMEs"), definidas como princípios ativos originais, sem registro ou comercialização prévia nos EUA. Os demais $66 \%$, em sua maioria, correspondiam a aplicações de novas formulações de fármacos previamente aprovados. Estes dados são corroborados pela afirmativa de K. Maggon ${ }^{18}$ de que somente cerca de $30 \%$ de todas as novas 
entidades químicas ("New Chemical Entities, NCEs") aprovadas seriam de fato inovadoras.

A identificação de NCEs seguras e eficazes para um determinado alvo terapêutico, constituí o principal foco das indústrias farmacêuticas. Os requisitos básicos para um NCE de uso oral incluem boa biodisponibilidade, potência intrínseca, ausência de toxicidade e vantagens significativas, quando comparado à terapia usual, para o tratamento da doença alvo. Embora seja possível prever, com base em estudos pré-clínicos, o perfil de um NCE quando administrado em humanos, por via oral, seu potencial de ação completo não será conhecido até que seja testado nas diferentes etapas de ensaios clínicos. Estima-se que a taxa de insucesso deste processo seja superior a 90\%. As principais razões incluem perda de eficácia clínica, propriedades farmacocinéticas inadequadas, toxicidade, reações adversas, razões comerciais e limitações farmacotécnicas ${ }^{19,20}$.

Em termos organizacionais, um NCE é identificado no estágio de desenvolvimento pré-clínico dos programas de descoberta de fármacos. O sucesso nesta etapa, incluindo avaliação favorável das propriedades farmacocinéticas (ADMET), levará à solicitação de aplicação para investigação de novos fármacos ("Investigational New Drug Application, IND"), permitindo a completude da fase de desenvolvimento, através da realização de ensaios clínicos com o NCE selecionado. Vencendo as três fases de ensaios clínicos, uma solicitação de nova aplicação de fármaco ("New Drug Application, NDA") é realizada e após aprovação pelas agências regulatórias (e.g. ANVISA - brasileira, FDA - americana, EMEA - européia), eventualmente, o fármaco entrará no mercado.

A taxa de sucesso de NCEs, desde da etapa de descoberta até o estágio de desenvolvimento pré-clínico, pode variar de 1 a cada 100 ou 1 a cada 5000 compostos $^{20}$. Das solicitações de IND o sucesso estimado varia de 13\% para Fase 1 de ensaios clínicos, $40 \%$ para Fase 2 e $80 \%$ para Fase 3. Com base nestes dados estima-se que 1 em cada 25 NCEs, que adquirem o status de IND, se tornará um fármaco comercializado, revelando um processo de baixo índice de sucesso ${ }^{21,22}$.

\section{Desafios para aumento da produtividade e racionalidade do processo da descoberta de fármacos, segundo o paradigma industrial}

Os dois principais gargalos do processo de descoberta e desenvolvimento de fármacos consistem na transformação do hit ao protótipo - ainda na etapa de descoberta - e na passagem do protótipo (NCE) a candidato a fármaco (NID), durante a etapa de desenvolvimento. $\mathrm{O}$ primeiro diretamente influenciado pelo modus operandis do paradigma industrial da Química Medicinal.

Segundo prognóstico realizado por Joseph Mollica (diretor da "Pharmacopeia Drug Discovery", Inc), em 1996, a introdução da Química Combinatorial (CQ), nas indústrias farmacêuticas, levaria ao aumento expressivo da produtividade associada ao processo da descoberta de novos fármacos. Com base neste prognóstico, investimentos maciços foram feitos visando capacitar as empresas de grande e pequeno porte a adquirirem os equipamentos laboratoriais necessários à implementação da nova tecnologia. Milhares de livrarias combinatórias foram preparadas, mas, na prática, o impacto da nova tecnologia é freqüentemente posto em xeque, dado o insucesso na etapa de identificação de uma molécula pura, ativa, a partir do processo de desconvolução da mistura com atividade identificada por HTS. Ademais, cerca de $70 \%$ dos hits (ligantes) identificados neste processo fracassam na etapa de transformação ao protótipo ${ }^{23,24}$. A falta de diversidade química, ausência de propriedades do tipo fármaco ("druglike properties") e a seleção baseada em alvos moleculares não validados clinicamente representam as razões principais para o insucesso desta etapa.
Algumas estratégias visando racionalizar o processo de construção das diversas coleções ou livrarias combinatórias vêm sendo empregadas. A preparação de quimiotecas, racionais, pode ser alcançada através do planejamento prévio considerando o aumento da diversidade molecular ${ }^{25}$ e a preparação de compostos que sumarizem as propriedades intrínsecas de um protótipo ${ }^{26}$, através da aplicação de abordagens que permitam prever o comportamento farmacocinético dos hits identificados ${ }^{27-30}$.

Desta feita, nos últimos anos, a composição das diversas quimiotecas combinatórias vem sendo influenciada pela regra cunhada por Chris Lipinski, denominada regra dos 5 ("rule of five") que estabelece alguns parâmetros estruturais relevantes para a predição teórica do perfil de biodisponibilidade oral. Alternativas a esta regra incluem a determinação da área de superfície polar ("polar surface área") ou aplicação dos parâmetros Volsurf, utilizados para predição da absorção oral e penetração através da barreira hemato-encefálica. Outro aspecto estrutural que influencia de forma significativa a biodisponibilidade é a flexibilidade estrutural, que deve ser considerada no desenho racional das quimiotecas combinatórias $^{32,33}$.

Outro desafio para a racionalidade na aplicação da QC acoplada ao HTS parece depender da criação de sub-quimiotecas, nas quais os substituintes de um determinado arcabouço molecular são selecionados, de forma racional, de modo a permitir a criação de um banco de dados de relações entre a estrutura química e a atividade biológica $(\mathrm{SAR})^{34}$.

Para que um protótipo seja considerado um candidato a fármaco, evoluindo do processo de descoberta para a etapa de desenvolvimento, alguns fatores devem ser considerados, tais como: simplicidade estrutural - com possibilidade de modificações, visando a otimização de seu perfil farmacoterapêutico - ser membro de uma série congênere com SAR bem estabelecida; possuir situação patentária favorável e apresentar boa propriedade farmacocinética $(\mathrm{ADMET})^{26}$.

Estratégias para a diminuição da taxa de atrito na transformação do protótipo ao candidato a fármaco incluem a realização de ensaios farmacocinéticos e toxicológicos, nos estágios ainda mais iniciais do processo da descoberta de fármacos. A determinação do perfil de permeabilidade celular, solubilidade e estudos farmacocinéticos in silico - para predição das propriedades $\mathrm{ADMET}^{35}$ - são alternativas para contribuir com a seleção do protótipo de melhor perfil farmacoterapêutico.

Cumpre ressaltar que, a partir da seleção do protótipo, todas as ferramentas e estratégias utilizadas no processo de otimização e transformação do protótipo a candidato a fármaco são usualmente empregadas nos projetos de descoberta de fármacos baseados na aplicação do paradigma clássico da Química Medicinal, revelando sua área de sobreposição ao paradigma industrial.

\section{"Screening" virtual}

O processo de triagem orientado pelo alvo molecular, característico do paradigma industrial, vem sendo influenciado pela revolução da biologia molecular e pelos avanços da bioinformática. A habilidade de desenvolver modelos que predigam o reconhecimento molecular de uma micromolécula (ligante) por um determinado biorreceptor, associada à disponibilidade de amplo banco de dados virtual de pequenas moléculas e de proteínas no PDB, impulsionou o desenvolvimento de software para triagem in silico, aplicando-se a abordagem conhecida como "screening" virtual ${ }^{36-38}$.

Embora esta estratégia vise acelerar o processo de identificação de ligantes, contribuindo para o processo da descoberta de fármacos, a utilidade do método permanece limitada, tanto pelo valor quanti- 
tativo, previsto, como pelas diferenças entre as estruturas moleculares concebidas pelo programa, muitas vezes sem análise crítica do operador, com aquelas factíveis de serem sintetizadas.

Segundo Kubinyi ${ }^{39}$, o êxito na aplicação desta abordagem depende muito mais da descrição adequada das propriedades moleculares que do método específico utilizado. Embora a análise de farmacóforos e o "docking" (atracamento molecular) sejam técnicas importantes no processo de desenho racional de ligantes, candidatos a protótipos de fármacos, elas são frequientemente aplicadas de forma inadequada. Ademais, a complexidade do processo de interação ligante-receptor - considerando fatores entrópicos e entálpicos - a presença de moléculas de água, a flexibilidade do ligante e do sítio de interação são outros fatores complicadores, que podem comprometer a descrição quantitativa da interação, através da afinidade prevista pelos modelos de "docking".

Nas indústrias farmacêuticas, a utilização desta abordagem muita vezes tem como objetivo a identificação de novos ligantes (hits) para alvos moleculares conhecidos e com fármacos já descritos, visando identificar estruturas originais de alta afinidade pelo alvo selecionado. A estratégia de "screening" virtual é utilizada, no contexto da aplicação do paradigma-clássico, como ferramenta para determinação teórica de seletividade e para auxílio na etapa de otimização do protótipo.

Como outras estratégias de triagem maciça in vitro, o "screening" virtual, in silico, tem suscitado crítica quanto ao caráter racional da abordagem. Em 2003, Drews ${ }^{40}$, em trabalho sobre as tendências estratégicas das indústrias farmacêuticas, sugeriu a perda de individualidade, compromisso com a ciência, cultura e padrões éticos, motivada pela busca da quantidade em detrimento da qualidade, característica da aplicação do paradigma industrial no processo da descoberta de fármacos. Segundo Kubinyi ${ }^{39}$, estas atividades negligenciam a importância do cérebro como componente essencial ao processo de descoberta de fármacos e se baseiam em sistemas in vitro artificiais, na esperança de que informações geradas em pedaços possam representar partes de um todo. Ademais, conclui sobre a perda de expertise na Química Medicinal Clássica e em Farmacologia e sobre a incapacidade de se preservar, de forma sistemática, os conhecimentos adquiridos a partir de projetos antigos de descoberta de fármacos.

Mais recentemente, a estratégia de "screening" virtual vem sendo empregada dentro da abordagem conhecida por "in silico antitarget screening", visando contribuir para o aumento da taxa de acerto no processo de seleção de novos candidatos a fármacos (NCEs). Esta abordagem vem sendo utilizada como parâmetro para eliminação de ligantes pré-selecionados, a partir de uma atividade in vitro sobre um alvo terapêutico específico, importante para o controle e/ou tratamento de uma determinada doença, baseando-se num conjunto de informações geradas a partir da análise da atividade in silico sobre alvos reconhecidamente envolvidos com a resposta tóxica e efeitos adversos, permitindo antecipar um perfil de seletividade e ausência de toxicidade, que assegure o sucesso na etapa seguinte do processo da descoberta de fármacos ${ }^{37}$.

\section{Novas estratégias para a identificação do composto-protótipo}

A identificação do composto-protótipo constitui etapa chave no processo da descoberta de fármacos e objetivo primário da Química Medicinal. Ao longo dos anos, diversas estratégias foram utilizadas em sua identificação, incluindo: o "screening" sistemático de compostos naturais e sintéticos, eleitos em função da diversidade estrutural e dos ensaios biológicos disponíveis; otimização do hit identificado por HTS e através da aplicação das estratégias racionais de desenho molecular.
$\mathrm{Na}$ academia e na indústria farmacêutica a aplicação da estratégia de identificação do composto-protótipo baseada em modificações planejadas na estrutura de princípios ativos conhecidos - a partir de literatura científica, patentária, banco de dados de laboratório de pesquisa ou de empresa farmacêutica - é uma atividade bastante comum empregada no desenho de fármacos "me-too"2.

Outra estratégia para identificação do composto-protótipo explora as informações geradas pela observação clínica de efeitos adversos de fármacos comercializados ou em estudos de fase clínica. Esta estratégia permite identificar novas aplicações terapêuticas para fármacos já existentes, mesmo quando, ainda, não existam modelos farmacológicos em animais para avaliação das atividades observadas em humanos. Um exemplo de sucesso desta abordagem foi a descoberta da sildenafila (Viagra ${ }^{\circledR}$, Pfizer, Figura 1), originalmente planejada e desenvolvida para tratamento de doenças coronarianas e, posteriormente, comercializada para o tratamento da disfunção erétil ${ }^{42}$.

Mais recentemente, o processo de identificação do protótipo se beneficiou da estratégia de otimização seletiva dos efeitos adversos ("selective optimization of side activities, SOSA"), cunhada por Wermuth ${ }^{43}$, em 2004, cujo objetivo consiste em testar fármacos conhecidos ("old drugs") sobre novos alvos moleculares. Esta estratégia prevê a realização de "screening" farmacológicos para um número limitado de moléculas de fármacos, estrutural e terapeuticamente muito diversos, apresentando boa biodisponibilidade e ausência de toxicidade em humanos, diminuindo, desta forma, os riscos e os custos do processo de identificação do hit e de sua posterior otimização ao protótipo ${ }^{43}$.

O processo da descoberta de fármacos, segundo o paradigma industrial, é pautado na valorização de uma abordagem reducionista, baseada na filosofia de "um alvo - uma doença", culminando com a produção das chamadas "magic bullets", altamente seletivas, a exemplo do mesilato de imatinibe, Gleevec ${ }^{\circledast}$, Novartis, Figura 1), que revolucionou o tratamento da leucemia mielóide crônica ${ }^{44}$. Entretanto, nos últimos anos, essa visão reducionista tem sido revista, considerando que os mecanismos de ação celulares e bioquímicos associados a várias desordens fisiopatológicas têm características multifatoriais. Portanto, a eficácia no tratamento dessas doenças seria dependente de uma intervenção em mais de um alvo molecular, o que pode ser alcançado pelos chamados fármacos de ação múltipla, mistos, duplos ou simbióticos. Curiosamente, a maior parte dos fármacos modernos com ação múltipla foi descoberta fortuitamente e o mecanismo de ação elucidado a posteriori, a exemplo do antipsicótico olanzapina (Zyprexa ${ }^{\circledR}$, Eli Lilly, Figura 1). No entanto, o planejamento de fármacos ou protótipos simbióticos é possível e primariamente baseado no método de combinação de farmacóforos, a partir de ligantes ou de protótipos seletivos para os alvos previamente eleitos com base em seu papel na fisiopatologia que se pretende $\operatorname{tratar}^{2,45,46}$.

Outra abordagem atual empregada na identificação de novos protótipos é baseada no estudo do metabolismo de xenobióticos. Em tese, o principal objetivo do metabolismo de fármacos é a transformação de uma molécula farmacologicamente ativa em metabólitos hidrossolúveis inativos. Entretanto, não raro são os exemplos em que uma transformação metabólica conduz à formação de substâncias biologicamente ativas. O perfil farmacodinâmico, farmacocinético e toxicológico dos metabólitos ativos, identificados, pode ser superior, igual ou inferior ao fármaco que lhe deu origem. Quando identificados e realizados os estudos de atividade e segurança comparativos ao fármaco original, podem se tornar fármacos mais seguros e eficazes ou serem utilizados como molde molecular para o desenho de fármacos "me-too". Exemplos de metabólitos ativos, que se tornaram fármacos mais potentes, seguros e eficazes que o fármaco original, são relati- 
vamente abundantes e incluem a descoberta dos anti-histamínicos de segunda-geração fexofenadina (Allegra ${ }^{\circledR}$ ) a partir da terfenadina $\left(\right.$ Teldane $\left.^{\circledR}\right)$, desloratadina $\left(\right.$ Clarinex $\left.^{\circledR}\right)$ a partir da loratadina $\left(\right.$ Claritin $^{\circledR}$ ) (Figura 1) ${ }^{47}$

Por fim, outra abordagem nova que vem sendo explorada, nos últimos cinco anos, visando a identificação de protótipos é a estratégia fundamentada na descoberta baseada em fragmentos moleculares ("fragment-based discovery"), representando uma alternativa ao processo convencional da descoberta de fármacos. Nesta abordagem, trabalha-se com fragmentos - originários de coleções de quimiotecas selecionadas - de peso molecular (PM) inferior a $200 \mathrm{Da}$, baixa funcionalidade química e baixa afinidade $\left(\mathrm{IC}_{50}\right.$ da ordem de $\left.\mu \mathrm{M}-\mathrm{mM}\right)$ pelo alvo molecular, testado em experimentos in vitro. Uma vez identificada a capacidade de ligação de um fragmento molecular, também chamado de "scaffold" 48 , a uma proteína alvo, este fragmento é selecionado e paulatina e planejadamente funcionalizado, utilizando estratégias clássicas da Química Medicinal. Estima-se que para a otimização da atividade do fragmento original, representado por um aumento de afinidade de 3-5 ordens de magnitude em relação à afinidade inicial encontrada, seja necessária a síntese de um número inferior a 100 análogos funcionalizados ${ }^{49}$. Após aferição da atividade in vivo, o ligante identificado através da estratégia de descoberta baseada em fragmentos moleculares passa a ser denominado protótipo.

\section{Status da Química Medicinal Brasileira}

Na perspectiva de traçar o estado da arte da Química Medicinal no Brasil foi realizada uma busca sistemática, no banco de dados do portal Web of Science ${ }^{\circledR} 7.10$ (http://portal.isiknowledge.com), por palavras-chave eleitas de acordo com sua abrangência e adequação aos princípios, objetivos e definições da Química Medicinal, nos últimos 47 anos. Alguns artifícios para tratamento dos resultados gerados foram aplicados e serão relatados no contexto da discussão dos resultados finais.

O mapeamento dos Grupos de Pesquisa em Química Medicinal do país foi realizado através de busca no diretório de Grupo de Pesquisa do CNPq (http://www.cnpq.br/gpesq), utilizando como filtro os 27 Estados da Federação, e os resultados serão discutidos adiante.

Em abordagem inicial, pretendeu-se determinar o percentual de contribuição brasileira na produção de trabalhos científicos na área da Química Medicinal, estabelecendo-se como parâmetros para busca, no portal Web of Science ${ }^{\circledR} 7.10$, seis palavras-chave - composto-líder ou protótipo ("lead-compound or prototype"); planejamento ("design"); modelagem molecular ("molecular modeling"); síntese ("synthesis"); ensaios farmacológicos ("pharmacological assays"); ADME (“ADME”) - e o período de análise: 1960-1969, 1970-1979, 1980-1989, 1990-1999 e 2000-2007. Após a observação e quantificação do número total de artigos gerados por período de análise e palavra-chave utilizada, os dados foram analisados pela aplicação subseqüente de dois filtros - seleção do país da publicação ("country/territory= Brazil") e classificação do artigo ("subject category = Medicinal Chemistry") - de modo a permitir o mapeamento mais preciso da contribuição nacional no total de artigos encontrados, estabelecendo-se neste total o percentual relacionado a trabalhos classificados na categoria de Química Medicinal.

Os resultados, esquematizados na Tabela 1 , revelam contribuições significativas de pesquisadores brasileiros na produção de conhecimento vinculado às palavras-chave selecionadas, com maior ou menor impacto quantitativo de acordo com a década analisada. Observa-se, ainda, que a contribuição é crescente ao longo das décadas, independente da palavra-chave utilizada. Entretanto, pequeno percentual deste conhecimento refere-se a trabalhos classificados na categoria de Química Medicinal.
A exceção dos dados encontrados com o termo síntese ("synthesis"), para todas as demais palavras-chave a participação brasileira no contexto da geração de trabalhos classificados como Química Medicinal é significativa apenas a partir da década de 90, intensificando-se nos anos 2000. Esse dado, tendencioso, pode sugerir a interpretação errônea de que a Química Medicinal brasileira tenha se iniciado neste período. Entretanto, conforme evidenciado na Tabela 1, os primeiros trabalhos de Química Medicinal realizados por pesquisadores brasileiros datam da década de 70, encontrados somente pelo uso da palavra-chave síntese. A análise destes 5 trabalhos, correspondendo a $4,5 \%$ de todas as publicações brasileiras do período de 1970-1979, contendo a palavra-chave síntese, revela que, curiosamente, $75 \%$ deste total foram desenvolvidos por pesquisadores da Escola Paulista de Medicina e os resultados publicados na revista científica mais prestigiosa da área, o Journal of Medicinal Chemistry, abordando aspectos relacionados com a síntese de derivados peptídicos com atividade sobre o sistema reninaangiotensina ${ }^{50-53}$. Enquanto, o quinto trabalho foi desenvolvido por pesquisadores do Instituto Militar de Engenharia e, ao contrário dos anteriores, não agregava aspectos farmacológicos às substâncias estudadas, tendo sido publicado na revista Chemical and Pharmaceutical Bulletin ${ }^{54}$.

Na década de 80 a contribuição da Escola Paulista de Medicina decai para 33,3\% ${ }^{55}$ do total de 3 publicações em Química Medicinal - utilizando a mesma palavra-chave - e desaparece nas décadas seguintes. Os demais 66,6\% da produção gerada nos anos de 1980 1989 referem-se a dois trabalhos. O primeiro realizado em uma colaboração internacional entre os laboratórios do Prof. C. Luuduc, em Grenoble - Fr, e Prof. I. Pitta, da UFPE, publicado na revista European Journal of Medicinal Chemistry ${ }^{56}$, e o segundo desenvolvido no Instituto de Química da Universidade de São Paulo SP, publicado no Journal of Pharmaceutical Sciences, sem referência a planejamento e/ou atividade farmacológica dos compostos sintetizados ${ }^{57}$.

Visando obter informações mais fidedignas do impacto qualitativo e quantitativo da produção científica nacional na área de Química Medicinal, foram eleitas as cinco revistas de maior índice de impacto da área - Journal of Medicinal Chemistry (JMC), Current Medicinal Chemistry (CMC), Bioorganic Medicinal Chemistry (BMC), Bioorganic Medicinal Chemistry Letters (BMCL) e European Journal of Medicinal Chemistry (EJMC) - e realizada busca, no portal Web of Science $^{\circledR} 7.10$ (http://portal.isiknowledge.com, acesso em Julho de 2007), por cada uma das palavras-chave previamente selecionadas de acordo com os critérios anteriormente relatados, i.e. fármaco ("drug"), composto-líder ou protótipo ("lead-compound or prototype"), planejamento ("design"), síntese ("synthesis") e ensaios farmacológicos ("pharmacological assays"). As informações geradas foram analisadas utilizando como filtro o país da publicação ("country/ territory = Brazil"). Após este procedimento, analisou-se a origem de cada trabalho mediante endereço do autor principal, a fim de permitir o mapeamento dos locais e Estados onde o conhecimento na área de Química Medicinal é gerado no país. Artigos com pesquisadores brasileiros, mas com autoria principal de pesquisadores estrangeiros não foram considerados na análise.

Conforme evidenciado na Tabela 2, o percentual de contribuição nacional na produção total de artigos em cada periódico selecionado, por década analisada, gerado a partir de busca com quaisquer das palavras-chave eleitas, é discreto, porém, observa-se expressivo aumento nos anos 2000. A relação numérica desta contribuição encontra-se ilustrada no Gráfico 1.

A participação das instituições de ensino superior (IES) e instituições de pesquisa nacionais na autoria principal dos trabalhos, resultantes da busca com os parâmetros definidos (Tabela 2 e Grá- 
Tabela 1. Número de publicações (artigos) geradas por palavra-chave, pesquisada nos períodos de 1960-1969; 1970-1979; 1980-1989; 1990-1999; 2000-2007. Percentual de contribuição brasileira e de trabalhos classificados na categoria de Química Medicinal. Pesquisa realizada no banco de dados do portal Web of Science ${ }^{\circledR} 7.10$ (http://portal.isiknowledge.com, acesso em Julho de 2007)

\begin{tabular}{|c|c|c|c|c|}
\hline Palavras-Chave $^{\mathrm{a}}$ & Período & $\begin{array}{c}\text { Total de } \\
\text { publicações/década }\end{array}$ & $\begin{array}{l}\text { \% de contribuição } \\
\text { brasileira } / \text { décadas }\end{array}$ & $\begin{array}{c}\% \text { de trabalhos } \\
\text { classificados como artigos de } \\
\text { Química Medicinal }{ }^{c}\end{array}$ \\
\hline \multirow[t]{5}{*}{ "lead-compound or prototype" } & 1960-1969 & 178641 & $\mathbf{0 \%}$ & $0 \%$ \\
\hline & $1970-1979$ & & $0 \%$ & $0 \%$ \\
\hline & $1980-1989$ & 1.217 & $0,41 \%$ & 0\% \\
\hline & 1990-1999 & 17.960 & $0,85 \%$ & $0,6536 \%$ \\
\hline & $2000-2007$ & 25.584 & $1,43 \%$ & $3,27 \%$ \\
\hline \multirow[t]{5}{*}{ "design" } & $1960-1969$ & 9.025 & $0,01 \%$ & $0 \%$ \\
\hline & $1970-1979$ & 23.265 & $0,095 \%$ & $0 \%$ \\
\hline & 1980-1989 & 39.861 & $0,2 \%$ & $0 \%$ \\
\hline & 1990-1999 & $>100.000$ & $1,117 \%$ & $0 \%$ \\
\hline & $2000-2007$ & $>100.000$ & $1,666 \%$ & $1,14 \%$ \\
\hline \multirow[t]{5}{*}{ "molecular modeling" } & 1960-1969 & 1 & $0 \%$ & $0 \%$ \\
\hline & 1970-1979 & 2 & $0 \%$ & $0 \%$ \\
\hline & 1980-1989 & 1 & $0 \%$ & $0 \%$ \\
\hline & 1990-1999 & 2.912 & $0,72 \%$ & $4,76 \%$ \\
\hline & $2000-2007$ & 3.965 & $1,51 \%$ & $3,33 \%$ \\
\hline \multirow[t]{5}{*}{ "synthesis" } & 1960-1969 & 32.685 & $0 \%$ & $\mathbf{0 \%}$ \\
\hline & 1970-1979 & 84.731 & $0,13 \%$ & $4,54 \%$ \\
\hline & $1980-1989$ & $>100.000$ & $0,287 \%$ & $1,045 \%$ \\
\hline & 1990-1999 & $>100.000$ & $\mathbf{0 , 8 8 5 \%}$ & $1,13 \%$ \\
\hline & $2000-2007$ & $>100.000$ & $1,468 \%$ & $3,81 \%$ \\
\hline \multirow[t]{5}{*}{ "pharmacological assays" } & 1960-1969 & 0 & $0 \%$ & $0 \%$ \\
\hline & $1970-1979$ & $\mathbf{0}$ & $0 \%$ & $0 \%$ \\
\hline & 1980-1989 & 6 & $0 \%$ & 0\% \\
\hline & 1990-1999 & 882 & $1,25 \%$ & $18,18 \%$ \\
\hline & $2000-2007$ & 1.205 & $2,82 \%$ & $14,7 \%$ \\
\hline \multirow[t]{5}{*}{ “ADME" } & 1960-1969 & 0 & $0 \%$ & $0 \%$ \\
\hline & $1970-1979$ & $\mathbf{0}$ & $0 \%$ & $0 \%$ \\
\hline & 1980-1989 & 2 & $0 \%$ & $0 \%$ \\
\hline & 1990-1999 & 23 & 0\% & $\mathbf{0 \%}$ \\
\hline & $2000-2007$ & 504 & $0,595 \%$ & $33,33 \%$ \\
\hline
\end{tabular}

aselecionado em função da abrangência e adequação aos princípios e definição da Química Medicinal; bdefinido por tratamento dos dados utilizando como filtro país da publicação (Brasil); 'definido por tratamento dos dados utilizando como filtro classificação da publicação (química medicinal).

fico 1), é bastante influenciada pela palavra-chave empregada, conforme ilustrado no Gráfico 2. As IES com maior percentual de contribuição para cada conjunto de resultados gerados foram a UFRJ, UFMG, USP-RP e UFPE (Gráfico 2).

Estes resultados foram, posteriormente, tratados realizandose o cruzamento entre todos os artigos gerados em cada conjunto de resultados, de modo a eliminar as duplicações eventuais e assegurar a precisão das informações. Desta feita, do total de 156 artigos gerados para os conjuntos individuais de resultados, foram encontrados 44 trabalhos repetidos que foram excluídos da análise final. Conforme representado no Gráfico 3, 21 IES e 2 instituições de pesquisa nacionais foram responsáveis pela geração dos 112 trabalhos encontrados e as instituições que mais contribuíram para a produção de conhecimento na área de Química Medicinal, utilizando os parâmetros de busca discutidos anteriormente, foram a UFRJ como 34\%, UFPE com 8,9\%, USP-SP com 8,0\%, USP-RP com $6,3 \%$. As demais instituições tiveram contribuições que variaram de 0,9 a $5,4 \%$.

A contribuição por Estado e Regiões da Federação Brasileira encontra-se ilustrada no Gráfico 4 e revela que $83 \%$ da produção científica na área de Química Medicinal é realizada na região sudeste.
De modo a obter um diagnóstico da inserção da Química Medicinal nas revistas científicas da Sociedade Brasileira de Química foi realizada uma busca no banco de dados do portal Web of Science ${ }^{\circledR} 7.10$, selecionando como parâmetros as revistas Química Nova (Quim. Nova) e Journal of the Brazilian Chemical Society (J. Braz. Chem. Soc.), o período 1960 a 2007 (período de análise anterior à criação das revistas Quim. Nova e J. Braz. Chem. Soc.) e as palavras-chave - fármaco ("drug"), composto-líder ou protótipo ("lead-compound or prototype"), planejamento ("design"), síntese ("synthesis") e ensaios farmacológicos ("pharmacological assays").

Os resultados gerados foram tratados inicialmente eliminando-se os trabalhos de autoria principal de pesquisadores estrangeiros. Posteriormente, realizou-se análise usando como filtro a classificação do artigo ("subject category"). Todos os artigos gerados, para cada conjunto de parâmetros selecionados, apresentaram a classificação de trabalhos multidisciplinares. Desta forma, fez-se necessária a avaliação manual das informações geradas, de modo a identificar os eventuais trabalhos com características, mesmo que parciais, da área de Química Medicinal, considerando sua definição proposta pela IUPAC.

Semelhante ao encontrado na busca nas revistas internacionais da área, a produção de artigos científicos de Química Medicinal, por 
Tabela 2. Número de publicações (artigos) geradas por palavra-chave, pesquisada nas cinco principais revistas de Química Medicinal indexadas, nos períodos de 1960-1969; 1970-1979; 1980-1989; 1990-1999; 2000-2007. Percentual de contribuição brasileira aferida no mesmo período utilizando como filtro o país da publicação ("country/territory= Brazil"). Pesquisa realizada no banco de dados do portal Web of Science ${ }^{\circledR} 7.10$ (http://portal.isiknowledge.com, acesso em Julho de 2007)

\begin{tabular}{|c|c|c|c|c|c|c|c|c|c|c|c|}
\hline \multirow[t]{2}{*}{ Palavra-chave $^{\mathrm{a}}$} & \multirow[t]{2}{*}{ Período } & \multicolumn{5}{|c|}{ Periódicos $\left(\mathrm{n}^{\mathrm{o}} \text { de trabalhos por periódicos }\right)^{\mathrm{b}}$} & \multicolumn{5}{|c|}{ Periódicos (\% de contribuição brasileira $)^{c}$} \\
\hline & & $\mathrm{JMC}$ & $\mathrm{CMC}$ & $\mathrm{BMC}$ & BMCL & EJMC & JMC & $\mathrm{CMC}$ & $\mathrm{BMC}$ & BMCL & EJMC \\
\hline \multirow[t]{5}{*}{ "drug" } & $1960-1969$ & 25 & 0 & 0 & 0 & 0 & $0 \%$ & $0 \%$ & $0 \%$ & $0 \%$ & $0 \%$ \\
\hline & $1970-1979$ & 34 & 0 & 0 & 0 & 9 & $0 \%$ & $0 \%$ & $0 \%$ & $0 \%$ & $0 \%$ \\
\hline & 1980-1989 & 39 & 0 & 0 & 0 & 15 & $0 \%$ & $0 \%$ & $0 \%$ & $0 \%$ & $0 \%$ \\
\hline & 1990-1999 & 62 & 50 & 104 & 104 & 109 & $0 \%$ & $0 \%$ & $0 \%$ & $0 \%$ & $0,917 \%$ \\
\hline & $2000-2007$ & 1.084 & 427 & 588 & 605 & 162 & $0,37 \%$ & $1,87 \%$ & $1,53 \%$ & $0,826 \%$ & $4,938 \%$ \\
\hline \multirow[t]{5}{*}{ "lead-compound or prototype" } & 1960-1969 & 1 & 0 & 0 & 0 & 0 & $0 \%$ & $0 \%$ & $0 \%$ & $0 \%$ & $0 \%$ \\
\hline & $1970-1979$ & 1 & 0 & 0 & 0 & 0 & $0 \%$ & $0 \%$ & $0 \%$ & $0 \%$ & $0 \%$ \\
\hline & 1980-1989 & 4 & 0 & 0 & 0 & 0 & $0 \%$ & $0 \%$ & $0 \%$ & $0 \%$ & $0 \%$ \\
\hline & 1990-1999 & 127 & 4 & 14 & 16 & 16 & $0 \%$ & $0 \%$ & $0 \%$ & $0 \%$ & $6,25 \%$ \\
\hline & $2000-2007$ & 199 & 12 & 116 & 26 & 7 & $1 \%$ & $0 \%$ & $4,3 \%$ & $3,84 \%$ & $18,18 \%$ \\
\hline \multirow[t]{5}{*}{ "design" } & 1960-1969 & 5 & 5 & 0 & 0 & 0 & $0 \%$ & $0 \%$ & $0 \%$ & $0 \%$ & $0 \%$ \\
\hline & $1970-1979$ & 22 & 22 & 0 & 0 & 2 & $0 \%$ & $0 \%$ & $0 \%$ & $0 \%$ & $0 \%$ \\
\hline & 1980-1989 & 83 & 83 & 0 & 0 & 5 & $0 \%$ & $0 \%$ & $0 \%$ & $0 \%$ & $0 \%$ \\
\hline & 1990-1999 & 921 & 921 & 68 & 25 & 80 & $0,1 \%$ & $0 \%$ & $0 \%$ & $0 \%$ & $1,25 \%$ \\
\hline & $2000-2007$ & 1.543 & 1.543 & 271 & 1.509 & 142 & $0,39 \%$ & $1,845 \%$ & $1,75 \%$ & $0,33 \%$ & $2,1127 \%$ \\
\hline \multirow[t]{5}{*}{ "synthesis" } & $1960-1969$ & 486 & 0 & 0 & 0 & 0 & $0 \%$ & $0,36 \%$ & $0 \%$ & $0 \%$ & $0 \%$ \\
\hline & $1970-1979$ & 1.103 & 0 & 0 & 0 & 175 & $0 \%$ & $0 \%$ & $0 \%$ & $0 \%$ & $0 \%$ \\
\hline & 1980-1989 & 1.283 & 0 & 0 & 0 & 357 & $0 \%$ & $0 \%$ & $0 \%$ & $0 \%$ & $0,28 \%$ \\
\hline & 1990-1999 & 2.505 & 32 & 504 & 2.308 & 696 & $0 \%$ & $0 \%$ & $0,17 \%$ & $0,17 \%$ & $0,718 \%$ \\
\hline & $2000-2007$ & 2.163 & 230 & 2.114 & 3.322 & 604 & $0,5 \%$ & $1,74 \%$ & $1,797 \%$ & $0,36 \%$ & $3,807 \%$ \\
\hline \multirow[t]{5}{*}{ "pharmacological assays" } & 1960-1969 & 0 & 0 & 0 & 0 & 0 & $0 \%$ & $0 \%$ & $0 \%$ & $0 \%$ & $0 \%$ \\
\hline & 1970-1979 & 0 & 0 & 0 & 0 & 0 & $0 \%$ & $0 \%$ & $0 \%$ & $0 \%$ & $0 \%$ \\
\hline & 1980-1989 & 0 & 0 & 0 & 0 & 0 & $0 \%$ & $0 \%$ & $0 \%$ & $0 \%$ & $0 \%$ \\
\hline & 1990-1999 & 66 & 3 & 6 & 6 & 10 & $0 \%$ & $0 \%$ & $0 \%$ & $0 \%$ & $0 \%$ \\
\hline & $2000-2007$ & 67 & 10 & 10 & 15 & 3 & $0 \%$ & $20 \%$ & $10 \%$ & $0 \%$ & $0 \%$ \\
\hline
\end{tabular}

${ }^{\mathrm{a}}$ selecionado em função da abrangência e adequação aos objetivos e definição da Química Medicinal; ${ }^{\mathrm{b}}$ definido por busca usando cada palavra-chave no período selecionado; ' definido por tratamento dos dados utilizando como filtro país da publicação (Brasil).

$\mathrm{JMC}=$ Journal of Medicinal Chemistry; $\mathrm{CMC}=$ Current Medicinal Chemistry; BMC $=$ Bioorganic Medicinal Chemistry; $\mathrm{BMCL}=\mathrm{Bioor}-$ ganic Medicinal Chemistry Letters; EJMC= European Journal of Medicinal Chemistry.
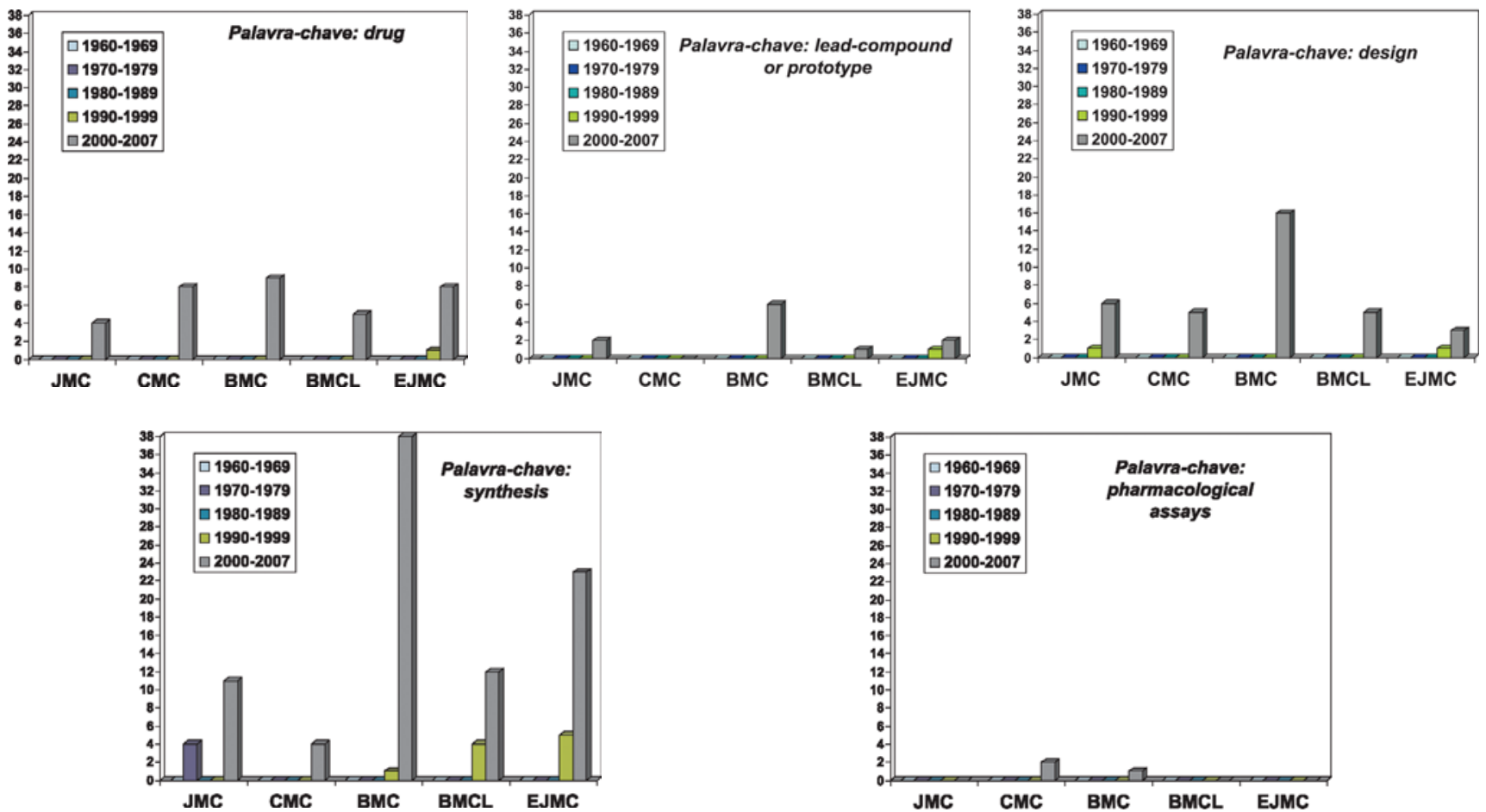

Gráfico 1. Representação do número de artigos brasileiros publicados nas cinco principais revistas de Química Medicinal [i.e. Journal of Medicinal Chemistry $(J M C)$, Current Medicinal Chemistry (CMC), Bioorganic Medicinal Chemistry (BMC), Bioorganic Medicinal Chemistry Letters (BMCL), European Journal of Medicinal Chemistry (EJMC)], no período de 1960-2007, utilizando as palavras-chave: drug, lead-compound or prototype, design, synthesis e pharmacological assays. Pesquisa realizada no banco de dados do portal Web of Science ${ }^{\circledast} 7.10$ (http://portal.isiknowledge.com, acesso em Julho de 2007) 

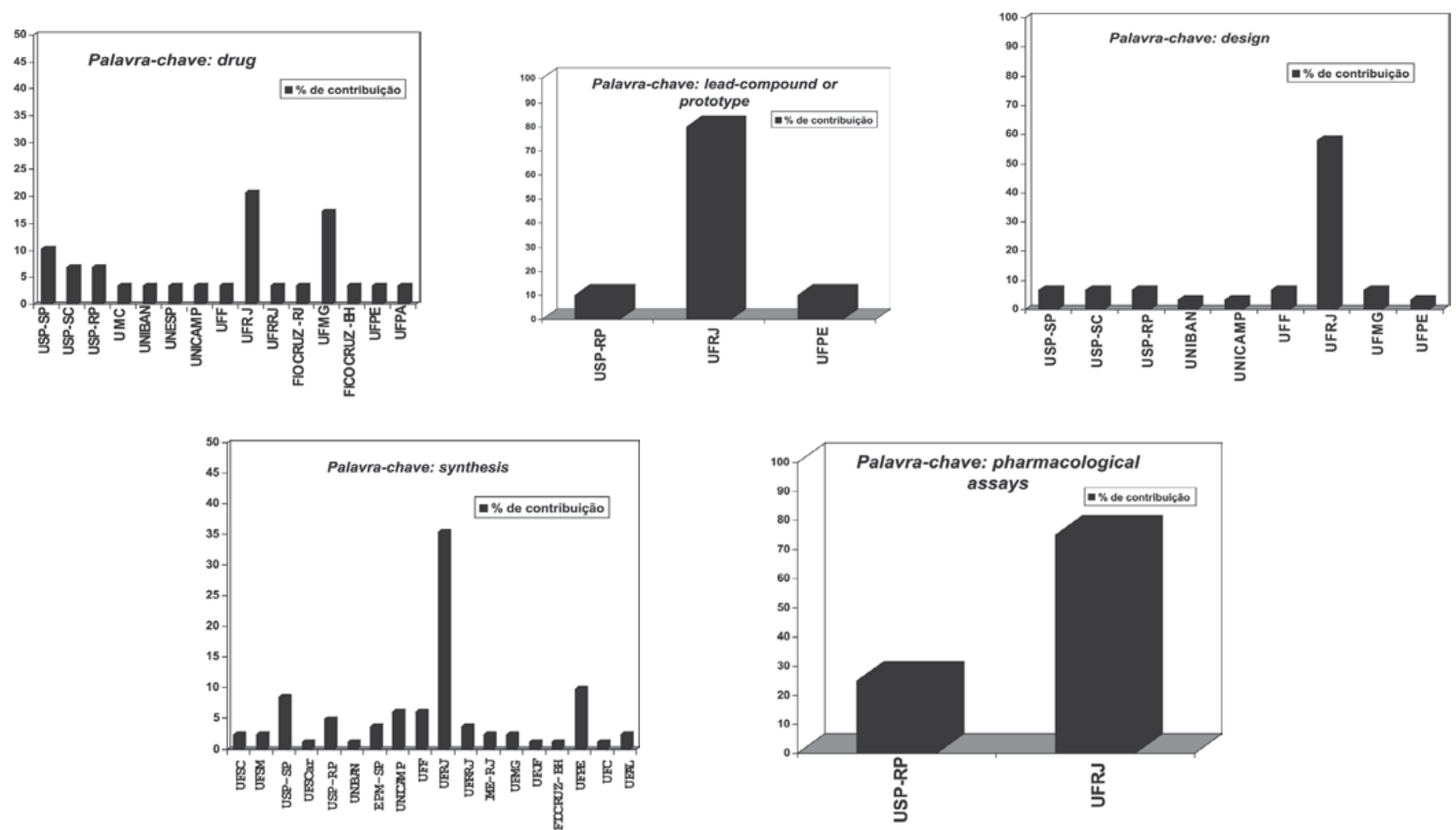

Gráfico 2. Representação da contribuição percentual das instituições de ensino superior e instituições de pesquisa nacionais na produção de artigos divulgados nas cinco principais revistas de Química Medicinal (i.e. Journal of Medicinal Chemistry, Current Medicinal Chemistry, Bioorganic Medicinal Chemistry, Bioorganic Medicinal Chemistry Letters, European Journal of Medicinal Chemistry), no período de 1960-2007, utilizando as palavras-chave: drug, leadcompound or prototype, design, synthesis e pharmacological assays. Pesquisa realizada no banco de dados do portal Web of Science ${ }^{\circledR} 7.10$ (http:// portal.isiknowledge.com, acesso em Julho de 2007)

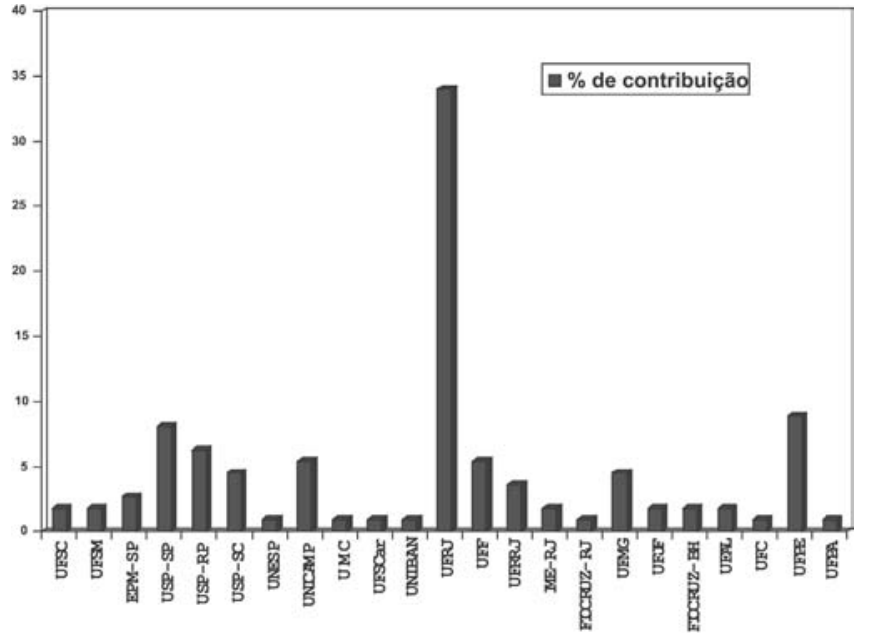

Gráfico 3. Representação da contribuição percentual total das instituições de ensino superior e instituições de pesquisa nacionais, na produção de artigos divulgados nas cinco principais revistas de Química Medicinal (i.e. Journal of Medicinal Chemistry, Current of Medicinal Chemistry, Bioorganic Medicinal Chemistry, Bioorganic Medicinal Chemistry Letters, European Journal of Medicinal Chemistry), no período de 1970-2007, utilizando as palavras-chave: drug, lead-compound or prototype, design, synthesis e pharmacological assays. Pesquisa realizada no banco de dados do portal Web of Science ${ }^{\circledR} 7.10$ (http:// portal.isiknowledge.com, acesso em Julho de 2007) e seleção manual para eliminação de duplicações/repetições nos distintos conjuntos de resultados obtidos através da busca utilizando cada palavra-chave eleita

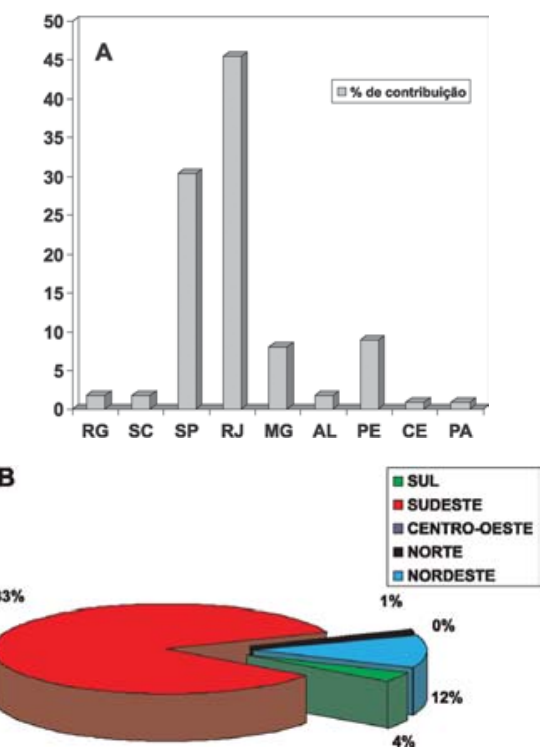

Gráfico 4. A) Representação da contribuição percentual total dos Estados da Federação Brasileira na produção de artigos divulgados nas cinco principais revistas de Química Medicinal (i.e. Journal of Medicinal Chemistry, Current Medicinal Chemistry, Bioorganic Medicinal Chemistry, Bioorganic Medicinal Chemistry Letters, European Journal of Medicinal Chemistry), no período de 19602007, utilizando as palavras-chave: drug, lead-compound or prototype, design, synthesis e pharmacological assays. B) Contribuição percentual total por Regiões da Federação Brasileira. Pesquisa realizada no banco de dados do portal Web of Science ${ }^{\circledR} 7.10$ (http://portal.isiknowledge.com, acesso em Julho de 2007) e seleção manual para eliminação de informações duplicadas nos distintos conjuntos de resultados obtidos através da busca utilizando cada palavra-chave eleita 
pesquisadores brasileiros, em Química Nova (Quim. Nova) e no Journal of the Brazilian Chemical Society (J. Braz. Chem. Soc.) inicia-se na década de 90 e torna-se mais expressiva nos anos 2000 (Tabela 3). No total, 138 resultados foram encontrados em Química Nova para as diferentes palavras-chave empregadas, no período previamente selecionado (Tabela 3 e Gráfico 5). Após análise para exclusão dos trabalhos duplicados ou repetidos, nos diferentes conjuntos de resultados, 86 artigos foram identificados e a participação das diferentes IES e instituições de pesquisa nacionais, na autoria principal destes trabalhos, foi determinada e encontra-se ilustrada no Gráfico 6. Conforme, evidenciado neste Gráfico, 26 IES e 1 instituição de pesquisa foram responsáveis pela divulgação do conhecimento em Química Medicinal na revista Química Nova, nos últimos 30 anos, com destaque para a UFRJ com $23 \%$ de contribuição, UFMG com $9,1 \%$, UNESP com $8,0 \%$, USP-RP com 5,7\%. As demais instituições apresentam contribuições da ordem de 1,2 a $4,6 \%$.

Tabela 3. Número de trabalhos brasileiros publicados nas revistas da Sociedade Brasileira de Química, i.e., Química Nova (Quim. Nova) e Journal of the Brazilian Chemical Society (JBCS), utilizando as palavras-chave: "drug", "lead-compound or prototype", "design", "synthesis" e "pharmacological assays"

\begin{tabular}{|c|c|c|c|c|c|c|c|c|c|c|}
\hline \multirow[b]{2}{*}{ Período } & \multicolumn{2}{|c|}{$\begin{array}{c}\text { Periódico / Busca por } \\
\text { palavra-chave: } \\
\text { "drug" }\end{array}$} & \multicolumn{2}{|c|}{$\begin{array}{c}\text { Periódico / Busca por } \\
\text { palavra-chave: } \\
\text { "lead-compound } \\
\text { or prototype" }\end{array}$} & \multicolumn{2}{|c|}{$\begin{array}{c}\text { Periódico / Busca por } \\
\text { palavra-chave: } \\
\text { "design" }\end{array}$} & \multicolumn{2}{|c|}{$\begin{array}{c}\text { Periódico / Busca por } \\
\text { palavra-chave: } \\
\text { "synthesis" }\end{array}$} & \multicolumn{2}{|c|}{$\begin{array}{c}\text { Periódico / Busca por } \\
\text { palavra-chave: } \\
\text { "pharmacological } \\
\text { assays" }\end{array}$} \\
\hline & Quim. Nova & JBCS & Quim. Nova & JBCS & Quim. Nova & JBCS & Quim. Nova & JBCS & Quim. Nova & JBCS \\
\hline 1960-1969 & 0 & 0 & 0 & 0 & 0 & 0 & 0 & 0 & 0 & 0 \\
\hline 1970-1979 & 0 & 0 & 0 & 0 & 0 & 0 & 0 & 0 & 0 & 0 \\
\hline 1980-1989 & 0 & 0 & 0 & 0 & 0 & 0 & 0 & 0 & 0 & 0 \\
\hline 1990-1999 & 16 & 0 & 2 & 0 & 10 & 0 & 15 & 8 & 0 & 0 \\
\hline $2000-2007$ & 40 & 0 & 3 & 0 & 25 & 0 & 26 & 12 & 1 & 0 \\
\hline
\end{tabular}
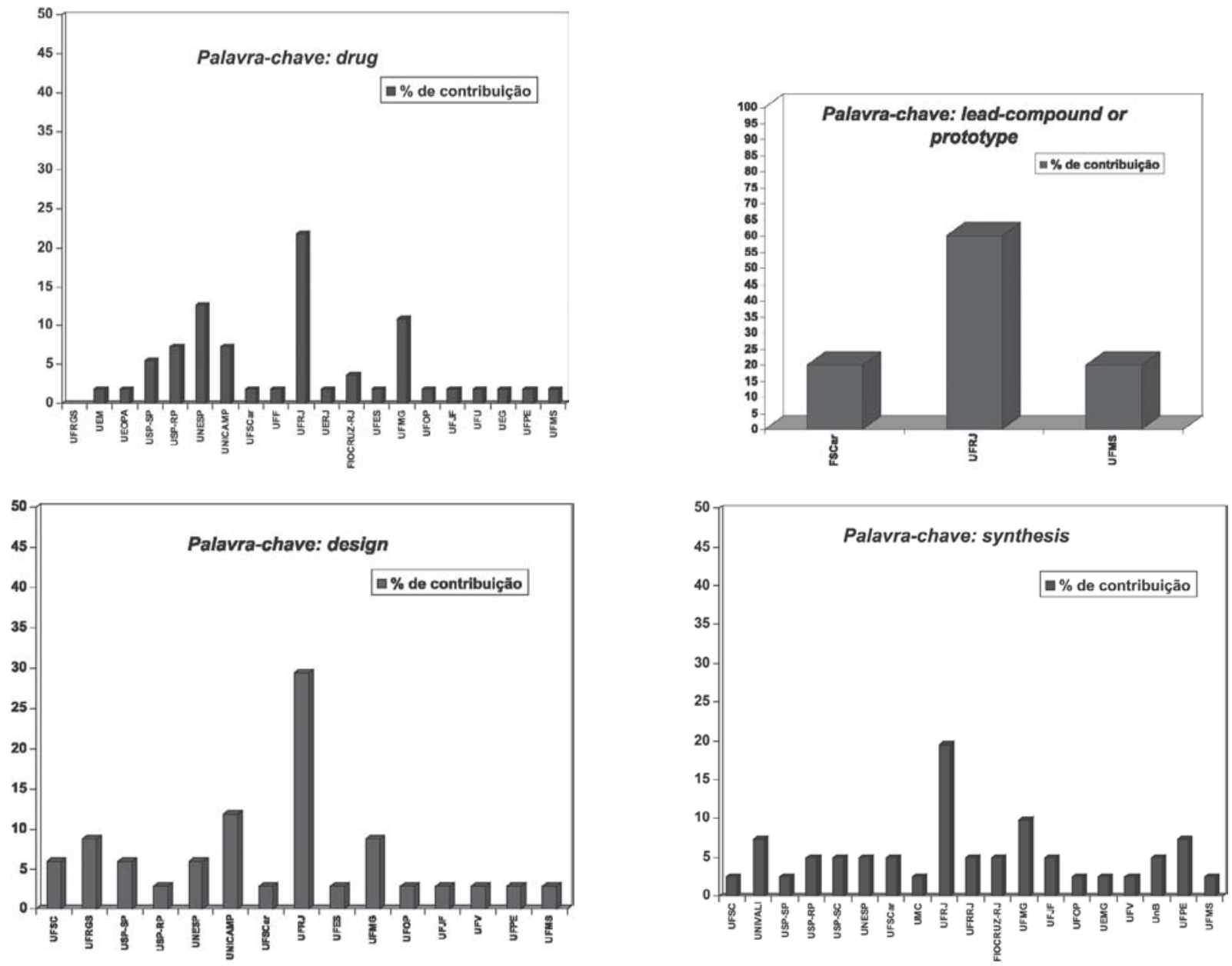

Gráfico 5. Representação da contribuição percentual das instituiçães de ensino superior e instituiçães de pesquisa nacionais na produção de artigos em Química Nova (Período: 1960-2007), utilizando as palavras-chave: drug, lead-compound or prototype, design e synthesis. Pesquisa realizada no banco de dados do portal Web of Science 7.10 (http://portal.isiknowledge.com, acesso em Julho de 2007) e seleção manual para identificação entre o total de artigos gerados daqueles com perfil de Química Medicinal, segundo definição da IUPAC 


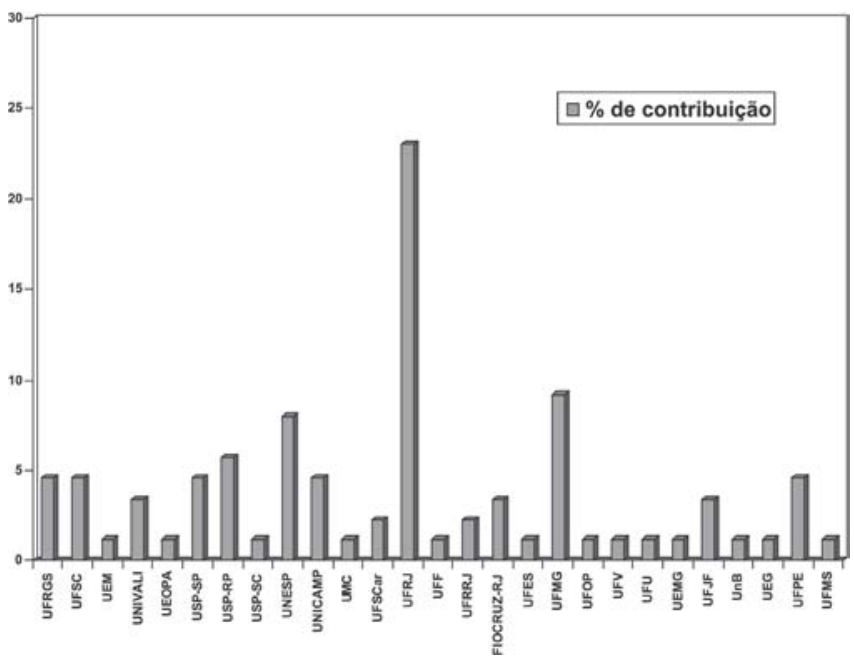

Gráfico 6. Representação da contribuição percentual total das instituições de ensino superior e instituições de pesquisa nacionais, na produção de artigos em Química Nova (Período: 1960-2007), utilizando as palavraschave: "drug","lead-compound or prototype", "design" $e$ "synthesis". Pesquisa realizada no banco de dados do portal Web of Science ${ }^{\circledR} 7.10$ (http:/ /portal.isiknowledge.com, acesso em Julho de 2007) e seleção manual para eliminação de informações duplicadas nos distintos conjuntos de resultados obtidos através da busca utilizando cada palavra-chave eleita

A fim de obter um diagnóstico destas publicações, foi realizada análise detalhada dos resultados encontrados em Química Nova nos últimos três anos (2005-2007). Do total de 24 publicações analisadas neste período, 14 referem-se a trabalhos de divulgação, 4 revisões, 3 artigos, 1 nota técnica, 1 trabalho de educação e 1 de assuntos gerais ${ }^{58,59}$. Dentre os trabalhos de divulgação e revisão observase uma ampla cobertura de temas relevantes na área de Química Medicinal, com destaque para aqueles relacionados ao papel do atropoisomerismo, da latenciação e do metabolismo no planejamento de fármacos, a importância dos produtos naturais e da aplicação de estratégias farmacotécnicas no contexto da Química Medicinal moderna $^{58,59}$. Os demais 6 trabalhos ( 3 artigos, 1 nota técnica, 1 trabalho de educação e 1 de assuntos gerais) são, ainda, mais heterogêneos, apresentando características parciais da área de Química Medicinal, segundo definição proposta pela IUPAC ${ }^{58,59}$.

Procedimento análogo foi realizado para busca no Journal of the Brazilian Chemical Society (J. Braz. Chem. Soc.) e nenhum resultado foi encontrado para as palavras-chave selecionadas, com exceção da palavra-chave síntese ("synthesis") (Tabela 3). Estes resultados, quando comparados àqueles encontrados para Química Nova, sugerem que o J. Braz. Chem. Soc. seja uma revista da Sociedade Brasileira de Química com tímida inclusão da Química Medicinal. Nos últimos 3 anos (2005-2007) foram encontrados 6 trabalhos com características da área de Química Medicinal, abordando a síntese de compostos bioativos com propriedades antimicrobianas ou antiproliferativas ${ }^{60}$. As instituições que mais contribuíram para a divulgação da Química Medicinal no J. Braz. Chem. Soc. foram a UFRJ com $35 \%$ de contribuição, UFMG com $20 \%$ e UFF com $10 \%$ (Gráfico 7). As outras 7 instituições tiveram contribuições de 5\% cada, equivalendo a 1 artigo nos 18 anos de criação da revista (Gráfico 7).

A busca no diretório de Grupo de Pesquisas do CNPq, consulta pela palavra Química Medicinal, revelou a existência de 44 Grupos de Pesquisa em Química Medicinal, distribuídos em 12 Estados da Federação, com maior concentração no Rio de Janeiro, Minas Gerais e São Paulo (Tabela 4). A área principal de atuação destes grupos é diversa, com predominância da Química e da Farmácia (Ta-

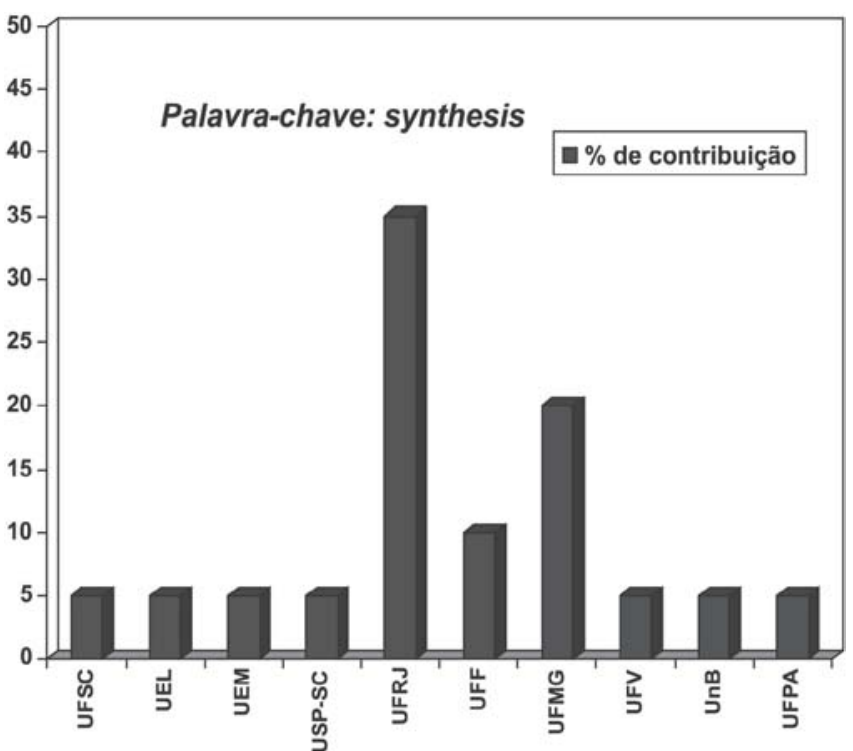

Gráfico 7. Representação da contribuição percentual das instituições de ensino superior nacionais na produção de artigos publicados no Journal of the Brazilian Chemical Society (Período: 1960-2007), utilizando a palavraschave: "synthesis". Pesquisa realizada no banco de dados do portal Web of Science $^{\circledR} 7.10$ (http://portal.isiknowledge.com, acesso em Julho de 2007) e seleção manual para identificação entre o total de artigos gerados daqueles com perfil de Química Medicinal, segundo definição da IUPAC

bela 4). A distribuição destes grupos por Regiões da Federação encontra-se ilustrada no Gráfico 8.

Curiosamente, a análise comparativa entre a distribuição dos grupos de pesquisa de Química Medicinal (Tabela 4) e as instituições promotoras de conhecimento científico na área, aferida através de publicações nos cinco principais periódicos internacionais de Química Medicinal (Gráfico 3), revela que os grupos situados nos estados do AC, AM, BA, GO, MS, TO não possuem produção científica internacional na área, dentro dos parâmetros e critérios considerados neste artigo. Embora no caso específico dos estados de GO e MS, produção, ainda que singela, em periódico nacional (i.e. Quim. Nova) tenha sido observada e atribuída a pesquisadores da UEG e UFMS.

Instituições de Ensino Superior de Estados sem grupos de pesquisa declarados em Química Medicinal, tais como AL, CE e PA, com participação na produção científica da área foram identificadas, a exemplo da UFAL, UFC e UFPA, com contribuição de $0,9 \%$ para cada instituição, equivalendo a uma publicação nos 47 anos avaliados (1960-2007), o que pode sugerir uma casualidade ou tendência

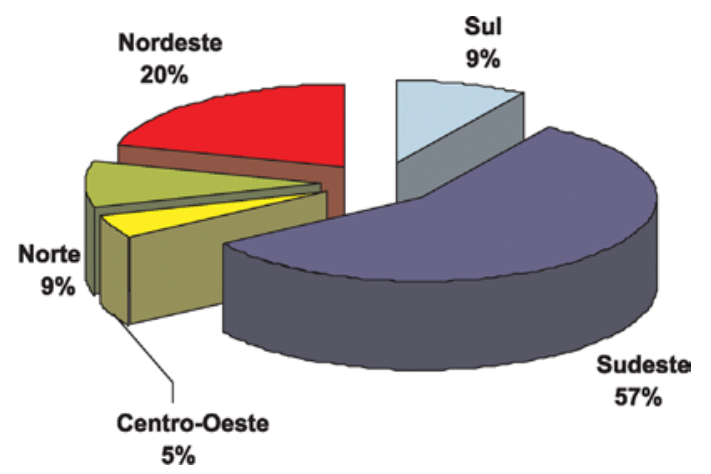

Gráfico 8. Relação percentual de Grupos de Pesquisa em Química Medicinal por Região da Federação 
Tabela 4. Relação do número de grupos de pesquisa em Química Medicinal por Estados da Federação Brasileira. Pesquisa realizada no Diretório de Grupos de Pesquisa do CNPq (www.cnpq.br/gpesq, acesso em Julho de 2007)

\begin{tabular}{|c|c|c|}
\hline $\begin{array}{l}\text { Estados da } \\
\text { Federação }\end{array}$ & $\begin{array}{l}\mathrm{N}^{\circ} \text { de Grupos de Pesquisa } \\
\text { em Química Medicinal }^{\mathrm{a}}\end{array}$ & Área Principal (AP) \\
\hline $\mathrm{AC}$ & 1 & Ecologia \\
\hline $\mathrm{AL}$ & 0 & - \\
\hline $\mathrm{AM}$ & 2 & Química (x 2) \\
\hline $\mathrm{AP}$ & 0 & - \\
\hline $\mathrm{BA}$ & 2 & $\begin{array}{c}\text { Ciência da Computação, } \\
\text { Química }\end{array}$ \\
\hline $\mathrm{CE}$ & 4 & $\begin{array}{c}\text { Química (x 3), } \\
\text { Bioquímica, }\end{array}$ \\
\hline DF & 0 & - \\
\hline $\mathrm{ES}$ & 0 & - \\
\hline GO & 2 & $\begin{array}{l}\text { Farmácia, } \\
\text { Química }\end{array}$ \\
\hline MA & 0 & - \\
\hline MG & 9 & $\begin{array}{l}\text { Química (x 6), } \\
\text { Farmácia (x 3) }\end{array}$ \\
\hline MS & 1 & Bioquímica \\
\hline MT & 0 & - \\
\hline PA & 0 & - \\
\hline PB & 0 & - \\
\hline PE & 3 & $\begin{array}{l}\text { Farmácia, } \\
\text { Química, } \\
\text { Botânica }\end{array}$ \\
\hline PI & 0 & - \\
\hline PR & 0 & - \\
\hline RJ & 10 & $\begin{array}{c}\text { Química (x 6), } \\
\text { Farmácia (x 2), } \\
\text { Farmacologia (x 2) }\end{array}$ \\
\hline $\mathrm{RN}$ & 0 & - \\
\hline RO & 0 & - \\
\hline RS & 1 & Farmácia \\
\hline RR & 0 & - \\
\hline $\mathrm{SC}$ & 3 & Química (x 3) \\
\hline SE & 0 & - \\
\hline SP & 6 & $\begin{array}{l}\text { Química (x 5), } \\
\text { Biofísica }\end{array}$ \\
\hline TO & 0 & - \\
\hline
\end{tabular}

abase corrente: grupos de pesquisa; consulta por: Química Medicinal (todas as palavras); filtro: UF

a um estágio embrionário para o surgimento de novos grupos em Química Medicinal.

A formação de recursos humanos na área de Química Medicinal é, ainda, incipiente no país. A nível de graduação a Química Medicinal é ensinada nos cursos de Farmácia, das Faculdades de Farmácia das diferentes instituições de ensino superior. A nível de pós-graduação, foi criado em março de 2007 o primeiro curso, inserido no Programa de Pós-Graduação em Farmacologia e Química Medicinal, do Instituto de Ciências Biomédicas (ICB) da Universidade Federal do Rio de Janeiro (UFRJ).

Outra importante iniciativa para a formação de recursos humanos na área da Química Medicinal é a Escola de Verão em Química Farmacêutica Medicinal (EVQFM), criada em 1995 com objetivo de complementar e atualizar estudantes - de graduação e pós-graduação - e profissionais, nos diferentes aspectos da disciplina, que observa contínua evolução. A descoberta e o planejamento de novos fármacos, assim como o estudo da relação entre a estrutura química e a atividade farmacológica de fármacos e medicamentos são os principais objetivos da EVQFM. Em sua décima edição recebeu o sub-comitê de Química Medicinal e Desenvolvimento de Fármacos da IUPAC, com especialistas ministrando o curso "highligths in medicinal chemistry".

\section{COMENTÁRIOS FINAIS}

A contribuição brasileira na geração de conhecimento novo na área da Química Medicinal é, ainda, tímida em termos numéricos, porém, com crescimento significativo a partir dos anos 2000. A ampla maioria é proveniente das pesquisas realizadas nas instituições de ensino superior (IES), federais e estaduais, com pequena participação de instituições de pesquisa da área da saúde, e mínima de IES privadas. A UFRJ é, de longe, a instituição mais produtiva na área da Química Medicinal, com base em todos os parâmetros de análise definidos neste artigo, representando importante liderança científica na área. Ademais esta instituição representa a vanguarda da Química Medicinal brasileira, com contribuições na criação da primeira Escola de Verão em Química Medicinal e do primeiro Programa de Pós-Graduação em Química Medicinal, datados de 1995 e 2007, respectivamente. O principal livro de Química Medicinal², em língua portuguesa, tem autoria de dois ilustres professores pesquisadores do estado do Rio de Janeiro.

\section{AGRADECIMENTOS}

Ao suporte financeiro do IM-INOFAR (CNPq-BR \#420.015/051), PRONEX (BR), FAPERJ (BR).

\section{REFERÊNCIAS}

1. Wermuth, C. G.; The Practice of Medicinal Chemistry, $2^{\text {nd }}$ ed., Academic Press: London, 2003, p. 29.

2. Barreiro, E. J.; Manssour, C. A. M.; Química Medicinal: As Bases Moleculares da Ação dos Fármacos, Art Med Editora Ltda: Porto Alegre, 2001, p. 83-122.

3. Barreiro, E. J.; Quim. Nova 2002, 25, 1172

4. Lima, L. M.; Barreiro, E. J.; Curr. Méd. Chem. 2005, 12, 23.

5. Cushman, D. W.; Cheung, H. S.; Sabo, E. F.; Ondetti, M. A.; The American Journal of Cardiology 1982, 49, 1390.

6. Ferreira, S .H.; Drugs 1985, 30, 1

7. Ondetti, M. A.; Williams, N. J.; Sabo, E. F.; Pluscec, J.; Weaver, E. R.; Kocy, O.; Biochemistry 1971, 10, 4033.

8. Ganellin, C. R. Em Chronicles of Drug Discovery; Bindra, J. S.; Lednicer, D., eds.; Wiley: New York, 1982, p. 1.

9. Pellecchia, M.; Sem, D. S.; Wuthrich, K.; Nat. Rev. Drug Discovery 2002, 1,211 .

10. Lombardino, J. G.; Lowe III, J. A.; Nat. Rev. Drug Discovery 2004, 3, 853.

11. Gershell, L. J.; Atkins, J. H.; Nat. Rev. Drug Discovery 2003, 2, 321.

12. Dias, R. L. A.; Corrêa, A. G.; Quim. Nova 2001, 24, 236.

13. Bunin, B. A.; Elman, J. A.; J. Am. Chem. Soc. 1992, 114, 1097.

14. Hardy, L. W.; Malikayil, A.; Curr. Drug Discovery 2003, 3, 15.

15. Lundstrom, K.; J.Cell. Molecular Medicine 2007, 11, 224; Sams-Dodd, F.; Drug Discovery Today 2006, $11,465$.

16. Milne, G. M.; Ann. Rep. Med. Chem. 2003, 38, 383.

17. Cohen, F. J.; Discovery Medicine 2005, 5, 153.

18. Maggon, K.; Drug Discovery Today 2005, 10, 739.

19. Hodgson, J.; Nat. Biotechnol. 2001, 19, 722

20. Prentis, R. A.; Lis, Y.; Walker, S. R.; Br. J. Clinical Pharmacol. 1998, 25, 387.

21. Cadwell, G. W.; Curr. Top. Med. Chem. 2001, 1, 353.

22. DiMasi, J. A.; Drug Information Journal 2000, 34, 1169

23. Jhoti, H.; Nat. Biotechnol. 2005, 23, 184

24. Lahana, R.; Drug Discovery Today 1999, 4, 447.

25. Ortholand, J-Y.; Ganesan, A.; Curr. Opin. Chem. Biol. 2004, 8, 271.

26. Oprea, T. I.; Davis, A. M.; Teague, S. J.; Leeson, P. D.; J. Chem. Inf. Computer Sci. 2001, 41, 1308.

27. Vieth, M.: Siegel, M. G.; Higgs, R. E.; Watson, I. A.; Robertson, D. H.; Savin, K. A.; Durst, G. L.; Hipskind, P. A.; J. Med. Chem. 2004, 47, 224. 
28. Veber, D. F.; Johnson, S. R.; Cheng, H-Y.; Smith, B. R.; Ward, K. W.; Kopple, K. D.; J. Med. Chem. 2002, 45, 2615.

29. Wenlock, M. C.; Austin, R. P.; Barton, P.; Davis, A. M.; Leeson, P. D.; J. Med. Chem. 2003, 46, 1250.

30. Walters, P. W.; Murcko, M. A.; J. Med. Chem. 1998, 41, 3314.

31. Lipinski, C. A.; Adv. Drug Delivery Rev.1997, 23, 3.

32. Ertl, P.; Rohde, B.; Selzer, P.; J. Med. Chem., 2000, 43, 3714.

33. Cruciani, G.; Pastor, M.; Guba, W.; Eur. J. Pharm. Sci. 2000, 11, S29.

34. Auld, D. S.; Diller, D.; Koc-Kan, H.; Drug Discovery Today 2002, 7, 1206.

35. Hansch, C.; Leo, A.; Mekapati, S. B.; Kurup, A.; Bioorg. Med. Chem.2004, 12,30 .

36. Barril, X.; Hubbard, R. E.; Morley, S. D.; Mini-Rev. Med. Chem. 2004, 4, 779.

37. Kitchen, D. B.; Decornez, H.; Furr, J. R.; Bajorath, J.; Nat. Rev. Drug Discovery 2004, 3, 935.

38. Muegge, I.; Oloff, S.; Drug Discovery Today: Technologies, 2006, 3, 405.

39. Kubinyi, H.; Nat. Rev. Drug Discovery 2003, 2, 665.

40. Drews, J.; Drug Discovery Today 2003, 8, 411.

41. Recanatini, M.; Bottegoni, G.; Cavali, A.; Drug Discovery Today: Technologies 2004, 1, 209.

42. Campbell, S. F.; Clinical Science 2000, 99, 255.

43. Wermuth, C.; J. Med. Chem. 2004, 47, 1303.

44. Lydon, N. B.; Druker, B.; Leukemia Research 2004, 28, 29.

45. Morphy, R.; Kay, C.; Rankovic, Z.; Drug Discovery Today 2004, 9, 641.

46. Morphy, R.; Rankovic, Z.; J. Med. Chem. 2005, 48, 6523.

47. Fura, A.; Shu, Y-Z.; Zhu, M.; Hanson, R. L.; Roongta, V.; Humphreys, W. G.; J. Med. Chem. 2004, 47, 4339.

48. Zhao, H.; Drug Discovery Today 2007, 12, 149.

49. Jhoti, H.; Nat. Biotechnol. 2005, 23, 184.

50. Paiva, A. C. M.; Nouailhetas, V. L. A.; Paiva, T. B.; J. Med. Chem. 1977 $20,898$.

51. Goissis, G.; Nouailhetas, V. L. A.; Paiva, A. C. M.; J. Med. Chem. 1976, $19,1287$.

52. Tominaga, M.; Stewart, J. M.; Paiva, T. B.; Paiva, A. C. M.; J. Med. Chem. 1975, 18, 130

53. Paiva, A. C. M.; Paiva, T. B.; Miyamoto, M. E.; J. Med. Chem. 1973, 16, 280.

54. Khan, M. A.; Rocha, E. K.; Chem. Pharm. Bull. 1977, 25, 3110.

55. Juliano, L.; Juliano, M. A.; de Miranda, A.; Chem. Pharm. Bull. 1987, 35, 2550

56. Galdino, S. L.; Pitta, I. D.; Luuduc, C.; Eur. J. Med. Chem. 1985, 20, 439.

57. Zanatta, N.; Rittner, R.; J. Pharm. Sci.1983, 72, 831.
58. Leite, A. C. L.; Santos, L. M. F.; Moreira, D. R. M.; Brondani, D. J.; Quim. Nova 2007, 30, 284; Pereira, D. G.; Quim. Nova 2007, 30, 171; dos Santos, A. R.; Pinheiro, A. C.; Sodero, A. C. R.; Cunha, A. S.; Padilha, M. C.; de Souza, P. M.; Fontes, S. P.; Veloso, M. P.; Fraga, C. A. M.; Quim. Nova 2007, 30, 125; Costa, M. S.; Kiralj, R.; Ferreira, M. M. C.; Quim. Nova 2007, 30, 25; Rodríguez, V.; Moura, S.; Pinto, E.; Pereira, C. M. P.; Braga, R. C.; Quim. Nova 2006, 29, 1365; Blau, L.; Menegon, R. F.; Chung, M. C.; Quim. Nova 2006, 29, 1307; de Souza, A. M. A.; Guarda, V. L. M.; Leite, L. F. C. C.; Filho, J. M. B.; de Lima, M. C. A.; Galdino, S. L.; Pitta, I. R.; Quim. Nova 2006, 29, 1106; Beck, R. C. R.; Haas, S. E.; Guterres, S. S.; Ré, M. I.; Benvenutti, E. V.; Pohlmann, A. R.; Quim. Nova 2006, 29, 990; Silveira, G. P.; Nome, F.; Gesser, J. C.; Sá, M. M.; Quim. Nova 2006, 29, 844; de Melo, E. B.; Carvalho, I.; Quim. Nova 2006, 29, 840.

59. Silva, H. S. R.; dos Santos, K. S. C. R.; Ferreira, E. I.; Quim. Nova 2006, 29, 776; Melo, J. O. F.; Donnici, C. L.; Augusti, R.; Ferreira, V. F.; de Souza, M. C. B. V.; Ferreira, M. L. G.; Cunha, A. C.; Quim. Nova 2006, 29, 569; Viegas Jr, C.; Bolzani, V. S.; Barreiro, E. J.; Quim. Nova 2006, 29, 326; Sena, M. M.; Trevisan, M. G.; Poppi, R. J.; Quim. Nova 2005, 28, 910; Borges, A. D. L.; Ponte, G. D.; Neto, A. F.; Carvalho, I.; Quim. Nova 2005, 28, 727; Frézard, F.; Schettini, D. A.; Rocha, O. G. F.; Demicheli, C.; Quim. Nova 2005, 28, 511; de Souza, M. V. N.; Vasconcelos, T. R. A.; Quim. Nova 2005, 28 , 678; Bonato, P. S. B.; Jabor, V. A. P.; Gaitani, C. M.; Quim. Nova 2005, 28, 683; Veiga-Jr, V. E.; Pinto, A. C.; Maciel, M. A. M.; Quim. Nova 2005, 28, 519; de Fátima, A.; Baptistella, L. H. B.; Pilli, R. A.; Modolo, L. V.; Quim. Nova 2005, 28, 306; de Almeida, V. L.; Leitão, A.; Reina, L. C. B.; Montanari, C. A.; Donnici, C. L.; Lopes, M. T. P.; Quim. Nova 2005, 28, 118; de Souza, M. V. N.; Ferreira, S. B.; Mendonça, J. S.; Costa, M.; Rabello, F. R.; Quim. Nova 2005, 28, 77; Verli, H.; Barreiro, E. J.; Quim. Nova 2005, 28, 95; Barreiro, E. J.; Fraga, C. A. M.; Quim. Nova 2005, 28, S56.

60. Magaton, A. S.; Rubinger, M. M. M.; Macedo-Jr, F. C.; Zambolim, L.; J. Braz. Chem.l Soc. 2007, 18, 284; Cunha, A. S.; Lima, E. L. S.; Pinto, A. C.; Esteves-Souza, A.; Echevarria, A.; Camara, C. A.; Vargas, M. D.; Torres, J. C.; J. Braz. Chem. Soc. 2006, 17, 439; Figueiredo, I. M.; dos Santos, L. V.; da Costa, W. F.; Carvalho, J. E.; da Silva, C. C.; Sacoman, J. L.; Kohm, L. K.; Sarragiotto, M. H.; J. Braz. Chem. Soc. 2006, 17, 954; Logrado, L. P. L.; Silveira, D.; Romeiro, L. A. S.; de Moraes, M. O.; Cavalcanti, B. C.; Costa-Lotufo, L. V.; Pessoa, C. O.; dos Santos, M. L.; J. Braz. Chem. Soc. 2005, 16, 1217; Boeck, P.; Sá, M. M.; de Souza, B. S.; Cercená, R.; Escalante, A. M.; Zachino, S. A.; Filho, V. C.; Yunes, R. A.; J. Braz. Chem. Soc. 2005, 16, 1360; Faria, T. J.; Silva, L. G. F.; Filho, J. D. S.; Chiari, E.; de Oliveira, A. B.; J. Braz. Chem.Soc. 2005, 16, 1415. 